CLINICAL STUDY

\title{
Amino acid properties may be useful in predicting clinical outcome in patients with Kir6.2 neonatal diabetes
}

\author{
Clementine S Fraser $^{1}$, Oscar Rubio-Cabezas ${ }^{1,2}$, Jennifer A Littlechild ${ }^{3}$, Sian Ellard ${ }^{1}$, Andrew T Hattersley ${ }^{1}$ \\ and Sarah E Flanagan ${ }^{1}$ \\ ${ }^{1}$ Department of Molecular Genetics, Institute of Biomedical and Clinical Science, Peninsula Medical School, University of Exeter, Barrack Road, \\ Exeter EX2 5DW, UK, ${ }^{2}$ Department of Endocrinology, Hospital Infantil Universitario Niño Jesús, Madrid, Spain and ${ }^{3}$ Henry Wellcome Building for \\ Biocatalysis, Biosciences, College of Life and Environmental Studies, University of Exeter, Exeter, UK \\ (Correspondence should be addressed to S E Flanagan; Email: sarah.flanagan@pms.ac.uk)
}

\begin{abstract}
Background: Mutations in the KCNJ11 gene, which encodes the Kir6.2 subunit of the $\beta$-cell $\mathrm{K}_{\mathrm{ATP}}$ channel, are a common cause of neonatal diabetes. The diabetes may be permanent neonatal diabetes mellitus (PNDM) or transient neonatal diabetes mellitus (TNDM), and in $\sim 20 \%$ of patients, neurological features are observed. A correlation between the position of the mutation in the protein and the clinical phenotype has previously been described; however, recently, this association has become less distinct with different mutations at the same residues now reported in patients with different diabetic and/or neurological phenotypes.

Methods: We identified from the literature, and our unpublished series, KCNJ11 mutations that affected residues harbouring various amino acid substitutions (AAS) causing differences in diabetic or neurological status. Using the Grantham amino acid scoring system, we investigated whether the difference in properties between the wild-type and the different AAS at the same residue could predict phenotypic severity.

Results: Pair-wise analysis demonstrated higher Grantham scores for mutations causing PNDM or diabetes with neurological features when compared with mutations affecting the same residue that causes TNDM $(P=0.013)$ or diabetes without neurological features $(P=0.016)$ respectively. In just five of the 25 pair-wise analyses, a lower Grantham score was observed for the more severe phenotype. In each case, the wild-type residue was glycine, the simplest amino acid.

Conclusion: This study demonstrates the importance of the specific AAS in determining phenotype and highlights the potential utility of the Grantham score for predicting phenotypic severity for novel KCNJ11 mutations affecting previously mutated residues.
\end{abstract}

European Journal of Endocrinology 167 417-421

\section{Introduction}

Neonatal diabetes mellitus (NDM) is a monogenic condition characterized by the onset of hyperglycaemia before 6 months of age. There are two main forms: transient NDM (TNDM), where the diabetes remits, and permanent NDM (PNDM), which is a chronic condition (1).

Activating mutations in the KCNJ11 and ABCC 8 genes, which encode the Kir6.2 and SUR1 subunits of the pancreatic $\beta$-cell ATP-sensitive potassium $\left(\mathrm{K}_{\mathrm{ATP}}\right)$ channel, are the most common cause of NDM accounting for $\sim 50 \%$ of all cases $(2,3,4,5,6,7)$. In the pancreatic $\beta$-cell, glucose metabolism results in an increase in the concentration of intracellular ATP. ATP binds to the Kir6.2 subunit of the $K_{\text {ATP }}$ channel initiating channel closure, membrane depolarization and ultimately insulin secretion. Activating mutations in KCNJ11 and ABCC8 cause NDM by reducing the sensitivity of the $\mathrm{K}_{\mathrm{ATP}}$ channel to ATP $(2,3)$.
The identification of a $\mathrm{K}_{\text {ATP }}$ channel mutation is clinically important as most patients can be treated with high-dose sulphonylureas, which close the channel independently of ATP resulting in improved glycaemic control $(8,9)$.

Approximately $20 \%$ of patients with KCNJ11 mutations have neurological features. These range from severe developmental delay and epilepsy diagnosed before 1 year (DEND syndrome) to a milder phenotype known as intermediate DEND syndrome (iDEND) (10). The neurological features are consistent with the expression of mutated $\mathrm{K}_{\text {ATP }}$ channels in neurons (11). In a minority of cases, the neurological features may be incidental or secondary to complications of diabetes such as ketoacidosis and severe hypoglycaemia (12).

Over 40 different activating mutations in the KCNJ11 gene have been reported (13). Previous studies have demonstrated a relationship between the position of the mutation and the incidence of neurological features, 
with mutations causing isolated diabetes more likely to occur in the ATP binding site and iDEND/DEND mutations often residing in the pore or the slide helix region of the Kir6.2 protein $(14,15,16)$. Recently, however, a few exceptions to this genotype/phenotype relationship have been described, and consequently, it is not possible to use the position of a novel KCNJ11 mutation within the protein to predict phenotype $(17,18)$. In addition, phenotypic variability associated with different mutations at the same residues has been reported. For example, a substitution of glutamine for arginine at codon 50 (R50Q) causes TNDM whereas a substitution to proline at the same residue (R50P) causes PNDM $(17,19)$. A second example is seen with mutations affecting codon 53 where a substitution of glycine to asparagine $(\mathrm{G} 53 \mathrm{~N})$ causes isolated diabetes while a substitution to an aspartic acid at the same residue (G53D) results in DEND syndrome (19, 20, 21).

As the specific amino acid substitution (AAS) is crucial in determining the phenotype, we have investigated whether there is a correlation between the phenotypic severity and the difference in biochemical properties of the various substituted amino acids at a given residue. In order to quantify differences in the amino acid properties, we used the Grantham matrix (22). This amino acid scoring system has traditionally been used to predict pathogenicity of novel missense variants, with high scores, which reflect large differences in the biochemical properties of the wild-type and the substituted amino acid, supporting causality (22).

\section{Materials and methods}

\section{Cohort}

Clinical characteristics of patients with an activating KCNJ11 mutation were collated from the literature and our unpublished series (13). All mutations affecting residues harbouring two or more different AAS, which resulted in a different diabetic or neurological status, were included in this study. A diabetic and neurological status was assigned to each mutation according to the majority phenotype.

\section{Clinical characterization}

Diabetic status was classified as i) TNDM if the diabetes had remitted or ii) PNDM if there was no remission of diabetes. Neurological status was classified as: i) isolated diabetes - no neurological involvement; ii) iDEND - developmental delay without generalized epilepsy diagnosed before 1 year; and iii) DEND developmental delay with generalized epilepsy diagnosed before 1 year.

To ensure robust classification, all patients under the age of 1 year at the time of the study were excluded

Table 1 All those patients with mutations at residues with multiple mutations from the Exeter data set and the literature are shown. The table displays the number of patients in each mutation group when the exclusion criteria is applied. Diabetic phenotype - the number and percentage of patients with 'TNDM' or 'PNDM' is shown for each mutation. Neurological phenotype - the number and percentage of patients with neurological features is shown for each mutation, this is then characterized into 'DEND' and 'iDEND'. Finally the Grantham score is displayed for each mutation.

\begin{tabular}{|c|c|c|c|c|c|c|}
\hline \multirow[b]{2}{*}{ Mutation } & \multirow[b]{2}{*}{$\begin{array}{l}\text { Grantham } \\
\text { score }\end{array}$} & \multicolumn{2}{|c|}{ Diabetic status } & \multicolumn{3}{|c|}{ Neurological status } \\
\hline & & $\begin{array}{l}\text { Patients } \\
\text { studied }(n)\end{array}$ & $\begin{array}{l}\text { TNDM or PNDM } \\
\text { majority phenotype }\end{array}$ & $\begin{array}{l}\text { Patients } \\
\text { studied }(n)\end{array}$ & $\begin{array}{l}\text { Isolated or neurological } \\
\text { features (NF) majority } \\
\text { phenotype }\end{array}$ & $\begin{array}{l}\text { Severity of neurological } \\
\text { features (iDEND or } \\
\text { DEND) majority } \\
\text { phenotype }\end{array}$ \\
\hline R50G & 125 & 1 & PNDM (100\%) & 1 & NF $(100 \%)$ & DEND (100\%) \\
\hline R50P & 103 & 3 & PNDM (100\%) & 4 & NF $(75 \%)$ & iDEND (66\%) \\
\hline R50Q & 43 & 7 & TNDM (100\%) & 7 & Isolated (100\%) & - \\
\hline G53D & 94 & 2 & PNDM (100\%) & 3 & NF $(100 \%)$ & DEND (100\%) \\
\hline G53N & 80 & 1 & PNDM (100\%) & 1 & Isolated (100\%) & - \\
\hline G53R & 125 & 2 & PNDM (100\%) & 2 & NF $(100 \%)$ & iDEND (100\%) \\
\hline G53S & 56 & 3 & TNDM (67\%) & 3 & Isolated (66\%) & - \\
\hline G53V & 109 & 3 & TNDM (100\%) & 3 & Isolated (100\%) & - \\
\hline V59G & 109 & 1 & PNDM (100\%) & 1 & NF $(100 \%)$ & DEND (100\%) \\
\hline V59M & 21 & 29 & PNDM (100\%) & 29 & NF $(93 \%)$ & iDEND (82\%) \\
\hline K170R & 26 & 2 & PNDM (100\%) & 2 & Isolated (100\%) & - \\
\hline K170T & 78 & 1 & PNDM (100\%) & 1 & Isolated (100\%) & - \\
\hline I182T & 89 & 1 & PNDM (100\%) & 1 & Isolated (100\%) & - \\
\hline I182V & 29 & 1 & TNDM (100\%) & 1 & Isolated (100\%) & - \\
\hline V252A & 64 & 4 & PNDM (75\%) & 2 & Isolated (100\%) & - \\
\hline V252G & 109 & 1 & PNDM (100\%) & 1 & NF $(100 \%)$ & iDEND (100\%) \\
\hline V252M & 21 & 2 & PNDM (50\%) & 2 & Isolated (100\%) & - \\
\hline G334C & 159 & 2 & PNDM (100\%) & 2 & Isolated (100\%) & - \\
\hline G334D & 94 & 2 & PNDM (100\%) & 2 & NF $(100 \%)$ & DEND (100\%) \\
\hline
\end{tabular}


from the dataset when i) the diabetes had not remitted or ii) neurological features had not been reported. Individuals were also excluded when their age was not known.

\section{Scoring differences in physicochemical properties of $A A S$}

The Grantham matrix was used to obtain a score for each AAS (range 5-215). The Grantham scores for each of the different AAS affecting the same residue were compared using the Wilcoxon test for pair-wise analysis.

\section{Results}

Seven residues (R50, G53, V59, K170, I182, V252 and G334) in the Kir6.2 protein were identified, which harboured different mutations in 71 patients with varying phenotypes (Table 1).

\section{Diabetic status}

Three residues (R50, G53 and I182) harboured ten different mutations causing TNDM $(n=4)$ or PNDM $(n=6)$ (Table 1). Pair-wise comparisons between TNDM and PNDM mutations at the same residue revealed a higher Grantham score for the PNDM mutation when compared with the TNDM mutation at the same residue in $77 \%(7 / 9)(P=0.013$; Table 1, Fig. 1a).

\section{Neurological features}

Five residues (R50, G53, K170, V252 and G334) harboured 16 different mutations causing isolated diabetes and diabetes with neurological features (Table 1). Pair-wise comparisons between the mutations revealed a higher Grantham score for the mutation associated with neurological features when compared with the mutation causing isolated diabetes at the same residue in $85 \%(11 / 13)(P=0.016$; Table 1 , Fig. $1 b)$.

Three residues (R50, G53 and V59) were identified, which harboured both iDEND and DEND mutations. In two of the three pair-wise comparisons, the Grantham score was higher for the mutations causing DEND syndrome (Fig. 1c).

\section{Discussion}

We have used the Grantham matrix to assess whether differences in the biochemical properties between wild-type and various substituted amino acids within Kir6.2 correlate with phenotype. Pair-wise analysis demonstrated higher Grantham scores for mutations causing PNDM $(P=0.013)$ or diabetes with neurological features $(P=0.016)$ when compared with
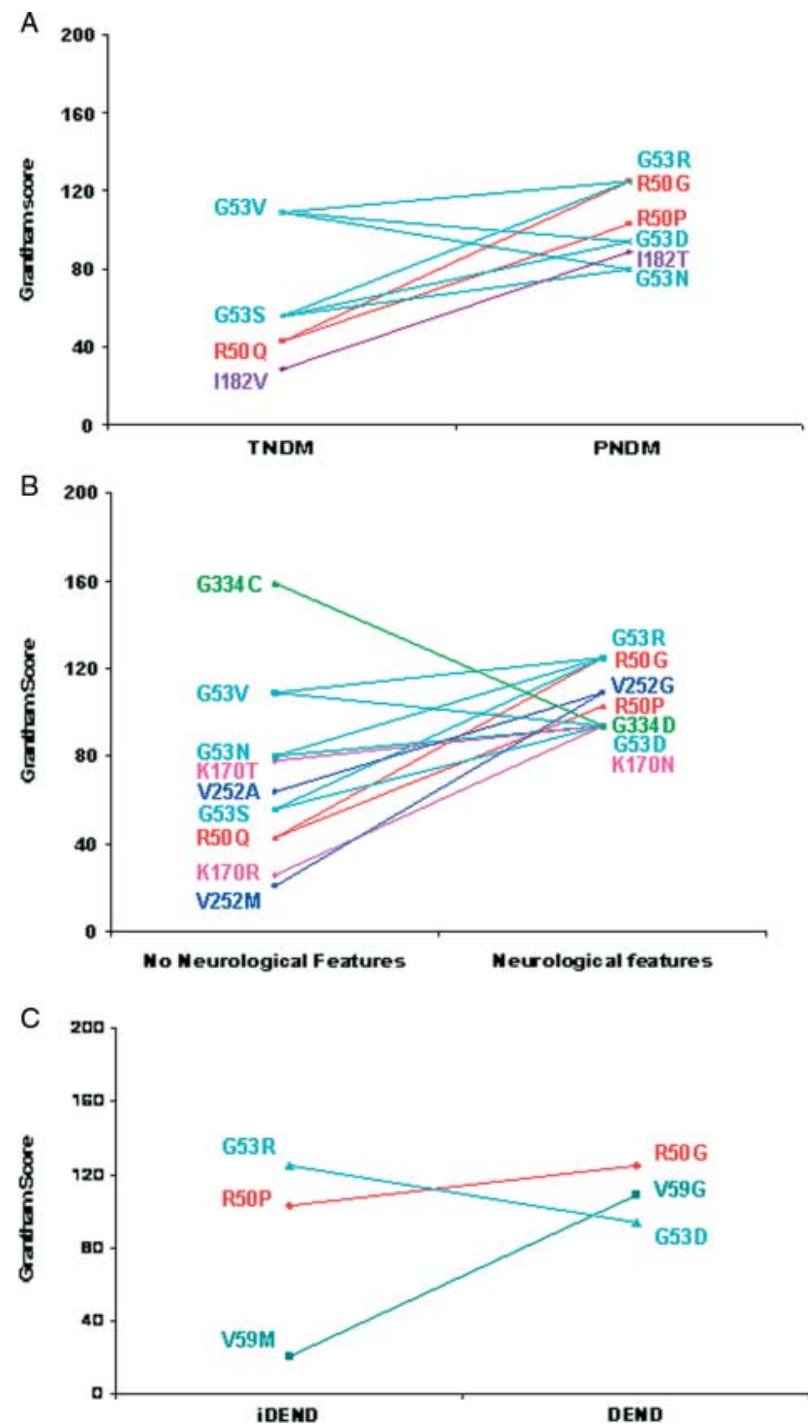

Figure 1 Graphs showing the difference in Grantham score for mutations at the same residue with differing phenotypes (pair-wise analysis). Graph A shows the pair-wise analysis of TNDM and PNDM mutations. Graph B shows the pair-wise analysis for mutations causing isolated diabetes and mutations associated with neurological features, and graph $\mathrm{C}$ shows the pair-wise analysis of mutations causing iDEND vs DEND syndrome.

mutations affecting the same residue associated with the milder phenotypes of TNDM or isolated diabetes respectively. The Grantham score was higher for DEND mutations when compared with iDEND mutations occurring at the same residue in two of the three cases.

In all five pair-wise analyses where lower Grantham scores were observed for the more severe phenotype, the wild-type residue in each case was glycine. As glycine is the simplest amino acid, any substitution will constitute a large change in biochemical properties and will therefore result in a high Grantham score. This result is in keeping with the study by Koster et al. (21) who demonstrated that all substitutions examined at residue 
G53 resulted in a decrease in affinity of the channel to ATP, thus supporting a crucial role for the glycine residue at this position. The Grantham scoring system should therefore be used with caution when trying to predict likely pathogenicity or disease severity for any mutations involving the substitution to or from a glycine residue.

The Grantham score has limited use in predicting severity of a single pathogenic mutation at any position within the gene as scores are variable between different residues and phenotypes. For example, the V59M mutation, which is associated with diabetes and neurological features, has a score of 21 , while the G53V mutation, which causes isolated diabetes, has a score of 109. Evidence from well-established sources, such as co-segregation within the family, the degree of conservation of the affected residue, and functional studies, when available, should therefore be sought before reporting the likely pathogenicity of novel Kir6.2 variants.

This study has highlighted the potential utility of the Grantham scoring system for predicting disease severity associated with different Kir6.2 mutations at the same residue. Our results support the findings of Zuberi et al. (23) who demonstrated that Grantham scores could predict disease severity in patients with epilepsy resulting from missense mutations at different residues in the SCN1A gene. Although further studies will be required on larger datasets to assess the robustness of this tool, when taken together the results from these two studies highlight the possible utility of the Grantham scoring system for predicting disease severity in the diagnostic setting. Analysis of Grantham scores may be particularly useful in the context of neonatal diabetes as the finding that patients with a KCNJ11 or ABCC8 mutation can be treated with sulphonylureas has resulted in a sharp increase in demand for genetic testing over recent years with many patients now referred for mutation analysis at the time of diagnosis. For patients in whom a previously reported mutation is identified, information on whether the diabetes is likely to be permanent or transient and whether neurological involvement is likely can be gleaned from case reports. However, for patients with a novel de novo missense mutation, it is not possible, in the absence of in vitro functional studies, to predict phenotype. Therefore, a tool such as the Grantham score may offer a useful insight into the likely clinical course of the diabetes in these patients.

Our study has a number of limitations. First, although information on the neurological phenotype was obtained from the referring clinician or from the literature, there is no globally accepted assessment for neurodevelopment. In addition, neurological features such as mild developmental delay are difficult to diagnose in younger children, and although we tried to minimize this influence by excluding those under 1 year in whom no neurological features had been reported, it is possible that the neurological status was misclassified in some of the patients. Finally, errors in the classification of diabetic status are possible with remissions being concealed by on-going low-dose treatment. It should also be noted that the genotype/ phenotype relationships may not be absolute as other genetic and environmental modifiers may influence disease severity.

In conclusion, this study demonstrates the importance of the biochemical properties of a substituted amino acid in determining phenotype. These results highlight the potential utility of an amino acid scoring system for predicting both diabetic and neurological phenotype by direct comparisons of Grantham scores for novel non-synonymous KCNJ11 mutations affecting previously mutated residues. Further studies investigating its use in predicting other aspects of phenotype, for example treatment response, or its use in other monogenic diseases, such as $A B C C 8$ neonatal diabetes or Crouzon syndrome $(13,24,25)$, where different mutations at the same residues cause variable phenotypes, are warranted.

\section{Declaration of interest}

The authors declare that there is no conflict of interest that could be perceived as prejudicing the impartiality of the research reported.

\section{Funding}

This research did not receive any specific grant from any funding agency in the public, commercial or not-for-profit sector. S E Flanagan was the Sir Graham Wilkins Peninsula Medical School Research Fellow. O Rubio-Cabezas holds a 'Miguel Servet' Research Fellowship funded by the Instituto de Salud Carlos III (CP11/00263). The research leading to these results has received funding from the European Community's Seventh Framework Programme (FP7/20072013) under grant agreement $n^{\circ} 223211$. (CEED3: Collaborative European Effort to Develop Diabetes Diagnostics).

\section{Acknowledgement}

The authors are grateful to Dr Beverley Shields for help with statistical analysis.

\section{References}

1 von Muhlendahl KE \& Herkenhoff H. Long-term course of neonatal diabetes. New England Journal of Medicine 1995333 704-708. (doi:10.1056/NEJM199509143331105)

2 Gloyn AL, Cummings EA, Edghill EL, Harries LW, Scott R, Costa T, Temple IK, Hattersley AT \& Ellard S. Permanent neonatal diabetes due to paternal germline mosaicism for an activating mutation of the KCNJ11 gene encoding the Kir6.2 subunit of the $\beta$-cell potassium adenosine triphosphate channel. Journal of Clinical Endocrinology and Metabolism 200489 3932-3935. (doi:10.1210/jc.2004-0568)

3 Proks P, Arnold AL, Bruining J, Girard C, Flanagan SE, Larkin B, Colclough K, Hattersley AT, Ashcroft FM \& Ellard S. A heterozygous activating mutation in the sulphonylurea receptor SUR1 (ABCC8) causes neonatal diabetes. Human Molecular Genetics 200615 1793-1800. (doi:10.1093/hmg/ddl101) 
4 Edghill EL, Flanagan SE, Patch AM, Boustred C, Parrish A, Shields B, Shepherd MH, Hussain K, Kapoor RR, Malecki M, MacDonald MJ, Stoy J, Steiner DF, Philipson LH, Bell GI, Hattersley AT \& Ellard S. Insulin mutation screening in 1,044 patients with diabetes: mutations in the INS gene are a common cause of neonatal diabetes but a rare cause of diabetes diagnosed in childhood or adulthood. Diabetes $2008 \quad 57$ 1034-1042. (doi:10.2337/db07-1405)

5 Flanagan SE, Patch AM, Mackay DJ, Edghill EL, Gloyn AL, Robinson D, Shield JP, Temple K, Ellard S \& Hattersley AT. Mutations in ATP-sensitive $\mathrm{K}^{+}$channel genes cause transient neonatal diabetes and permanent diabetes in childhood or adulthood. Diabetes 200756 1930-1937. (doi:10.2337/db070043)

6 Stoy J, Greeley SA, Paz VP, Ye H, Pastore AN, Skowron KB, Lipton RB, Cogen FR, Bell GI \& Philipson LH. Diagnosis and treatment of neonatal diabetes: a United States experience. Pediatric Diabetes 20089 450-459. (doi:10.1111/j.1399-5448. 2008.00433.x)

7 Babenko AP, Polak M, Cave H, Busiah K, Czernichow P, Scharfmann R, Bryan J, Aguilar-Bryan L, Vaxillaire M \& Froguel P. Activating mutations in the ABCC8 gene in neonatal diabetes mellitus. New England Journal of Medicine 2006355 456-466. (doi:10.1056/NEJMoa055068)

8 Pearson ER, Flechtner I, Njolstad PR, Malecki MT, Flanagan SE, Larkin B, Ashcroft FM, Klimes I, Codner E, Iotova V, Slingerland AS, Shield J, Robert JJ, Holst JJ, Clark PM, Ellard S, Sovik O, Polak M \& Hattersley AT. Switching from insulin to oral sulfonylureas in patients with diabetes due to Kir6.2 mutations. New England Journal of Medicine $2006 \quad 355 \quad 467-477$. (doi:10.1056/NEJMoa061759)

9 Rafiq M, Flanagan SE, Patch AM, Shields BM, Ellard S \& Hattersley AT. Effective treatment with oral sulfonylureas in patients with diabetes due to sulfonylurea receptor 1 (SUR1) mutations. Diabetes Care 200831 204-209. (doi:10.2337/dc071785)

10 Hattersley AT \& Ashcroft FM. Activating mutations in Kir6.2 and neonatal diabetes: new clinical syndromes, new scientific insights, and new therapy. Diabetes 200554 2503-2513. (doi:10.2337/ diabetes. 54.9.2503)

11 Clark RH, McTaggart JS, Webster R, Mannikko R, Iberl M, Sim XL, Rorsman P, Glitsch M, Beeson D \& Ashcroft FM. Muscle dysfunction caused by a $\mathrm{K}_{\text {ATP }}$ channel mutation in neonatal diabetes is neuronal in origin. Science $2010 \mathbf{3 2 9} 458-461$. (doi:10.1126/science.1186146)

12 Gloyn AL, Diatloff-Zito C, Edghill EL, Bellanne-Chantelot C, Nivot S, Coutant R, Ellard S, Hattersley AT \& Robert JJ. KCNJ11 activating mutations are associated with developmental delay, epilepsy and neonatal diabetes syndrome and other neurological features. European Journal of Human Genetics 200614 824-830. (doi:10.1038/sj.ejhg.5201629)

13 Flanagan SE, Clauin S, Bellanne-Chantelot C, de Lonlay P, Harries LW, Gloyn AL \& Ellard S. Update of mutations in the genes encoding the pancreatic $\beta$-cell K(ATP) channel subunits Kir6.2 (KCNJ11) and sulfonylurea receptor 1 (ABCC8) in diabetes mellitus and hyperinsulinism. Human Mutation 200930 170-180. (doi:10.1002/humu.20838)

14 Koster JC, Remedi MS, Dao C \& Nichols CG. ATP and sulfonylurea sensitivity of mutant ATP-sensitive $\mathrm{K}^{+}$channels in neonatal diabetes: implications for pharmacogenomic therapy. Diabetes 200554 2645-2654. (doi:10.2337/diabetes.54.9.2645)
15 Proks P, Antcliff JF, Lippiat J, Gloyn AL, Hattersley AT \& Ashcroft FM. Molecular basis of Kir6.2 mutations associated with neonatal diabetes or neonatal diabetes plus neurological features. PNAS 2004101 17539-17544. (doi:10.1073/pnas. 0404756101)

16 Gloyn AL, Pearson ER, Antcliff JF, Proks P, Bruining GJ, Slingerland AS, Howard N, Srinivasan S, Silva JM, Molnes J, Edghill EL, Frayling TM, Temple IK, Mackay D, Shield JP, Sumnik Z, van Rhijn A, Wales JK, Clark P, Gorman S, Aisenberg J, Ellard S, Njolstad PR, Ashcroft FM \& Hattersley AT. Activating mutations in the gene encoding the ATP-sensitive potassium-channel subunit Kir6.2 and permanent neonatal diabetes. New England Journal of Medicine 2004350 1838-1849. (doi:10.1056/NEJMoa032922)

17 Shimomura K, Girard CA, Proks P, Nazim J, Lippiat JD, Cerutti F, Lorini R, Ellard S, Hattersley AT, Barbetti F \& Ashcroft FM. Mutations at the same residue (R50) of Kir6.2 (KCNJ11) that cause neonatal diabetes produce different functional effects. Diabetes 200655 1705-1712. (doi:10.2337/db05-1640)

18 Masia R, Koster JC, Tumini S, Chiarelli F, Colombo C, Nichols CG \& Barbetti F. An ATP-binding mutation (G334D) in KCNJ11 is associated with a sulfonylurea-insensitive form of developmental delay, epilepsy, and neonatal diabetes. Diabetes 200756 328-336. (doi:10.2337/db06-1275)

19 Flanagan SE, Edghill EL, Gloyn AL, Ellard S \& Hattersley AT. Mutations in KCNJ11, which encodes Kir6.2, are a common cause of diabetes diagnosed in the first 6 months of life, with the phenotype determined by genotype. Diabetologia $2006 \mathbf{4 9}$ 1190-1197. (doi:10.1007/s00125-006-0246-z)

20 Vaxillaire M, Populaire C, Busiah K, Cave H, Gloyn AL, Hattersley AT, Czernichow P, Froguel P \& Polak M. Kir6.2 mutations are a common cause of permanent neonatal diabetes in a large cohort of French patients. Diabetes $2004 \mathbf{5 3}$ 2719-2722. (doi:10.2337/diabetes.53.10.2719)

21 Koster JC, Kurata HT, Enkvetchakul D \& Nichols CG. DEND mutation in Kir6.2 (KCNJ11) reveals a flexible N-terminal region critical for ATP-sensing of the $\mathrm{K}_{\text {ATP }}$ channel. Biophysical Journal 200895 4689-4697. (doi:10.1529/biophysj.108.138685)

22 Grantham R. Amino acid difference formula to help explain protein evolution. Science 1974185 862-864. (doi:10.1126/ science.185.4154.862)

23 Zuberi SM, Brunklaus A, Birch R, Reavey E, Duncan J \& Forbes GH. Genotype-phenotype associations in SCN1A-related epilepsies. Neurology 2011 76 594-600. (doi:10.1212/WNL.Ob013e31820 c309b)

24 Meyers GA, Day D, Goldberg R, Daentl DL, Przylepa KA, Abrams LJ, Graham JM Jr, Feingold M, Moeschler JB, Rawnsley E, Scott AF \& Jabs EW. FGFR2 exon IIIa and IIIc mutations in Crouzon, Jackson-Weiss, and Pfeiffer syndromes: evidence for missense changes, insertions, and a deletion due to alternative RNA splicing. American Journal Human Genetics 1996 58 491-498.

25 Park WJ, Meyers GA, Li X, Theda C, Day D, Orlow SJ, Jones MC \& Jabs EW. Novel FGFR2 mutations in Crouzon and Jackson-Weiss syndromes show allelic heterogeneity and phenotypic variability. Human Molecular Genetics 19954 1229-1233. (doi:10.1093/ $\mathrm{hmg} / 4.7 .1229)$

Received 13 March 2012

Revised version received 14 May 2012

Accepted 30 May 2012 